\title{
Research and Practice on Digitization Construction of University Archives
}

\author{
Ying Zhang \\ Jilin Agricultural University Archives \\ 474269500@qq.com
}

Keywords: University archives; Digitization; Construction

\begin{abstract}
The digital construction of archives in colleges and universities is the main body of archival building and development in the 21st century, which is an important part of the construction of "digital campus". This paper clarifies the significance of the digital construction of archives in colleges and universities, provides a practical and feasible operation plan for the process of the digitization in the university archives, and finds out the problems and solutions in the digital construction, so as to provide the shortcuts of the road to the digital construction for the university archives as a reference. Based on that, the university archives can provide information resources and social sharing services quickly and efficiently to promote the progressive realization of the digital file information resources, network management and multi-level multi-channel resources.
\end{abstract}

\section{Introduction}

At present, some colleges and universities led the management of backwardness, affected by the unit for the file with the professional staff too little, capital investment is not enough. In practice, access to digital files is not advanced equipment, and some even rely on a rare system for simple management, the lack of professional archives information technology guidance, the lack of law enforcement efforts. File information resource open sharing problem. With the development of the five major ideas, all levels of units of information on the degree of attention has been enhanced, the degree of social information has improved. However, due to the lack of standard specifications, the lack of ideas and funds led to the lack of important information on the development of the school records. Although some university archives departments have realized the importance and necessity of resource sharing, there are few cases of archival information sharing in management practice Have.

Digital Archives Network Infrastructure includes the system software and hardware, terminal and auxiliary equipment, network security prevention and other parts of the building. Infrastructure is an integral part of the overall network facilities, but the network security is not enough, no special network management center, more difficult for the digital archives equipped with sufficient internal LAN information points, so that data transmission, use, electronic file collection, archiving And resource security management and other work difficult to carry out. Resource display platform outside the network construction. There are a lot of colleges and universities have not yet established a professional file portal, even the school campus network is also very rare to see the file information Internet access query service function, can not be better set the direction, so that teachers and students interactive information, The convenience of the use of services contrary to the purpose.

By the university management system and the operation mechanism influence, the lack of archives information construction standards and top-level design, formed a fragmented, self-contained system, their own political situation. There is no unified body to coordinate the university archives network construction work, while the micro level of archives activities there is no uniform standard, there is a strong arbitrariness, digital file name is not standardized and other issues, inter-city exchanges and cooperation there are barriers to informatization ile development 
brings shackles. Digitized Archives Construction Content Differences. The actual work of the file resources "digital" to professional technical support, the storage of documents, audio and video, science and technology, education and teaching and other types of electronic archives and teaching management process generated by the entity file "virtual" format conversion, the information Record form "digital", and other digital archives resources together to manage and standardize the huge workload in less preparation staff can not be achieved.

\section{Research on the Digital Construction Content of Archives in Colleges and Universities.}

\section{Archives Management Automation}

Now many articles in the discussion of digital archives or virtual archives, the archives are more promising prospects and expectations, rarely involving the traditional archives of the modern management issues, archives management automation is the archives of their own management behavior of modern And this modernization is based on the computer digital management based on the computer instead of manually complete the business work will be widely used in computer archives automatic cataloging, automatic retrieval, automatic statistics, automatic identification and daily file management and other aspects of the work.

\section{The collection of Files for Digital Processing}

University archives in the construction funds are not sufficient circumstances, you can take the principle of resource priority, the purchase of a small amount of equipment, the important archives of the early digital processing, step by step and gradually expand the digital scale. Paper files can be digitized in two ways: the first is through the computer manual input or through the scanner scan by the character recognition software to identify the text file; the second is the file file every page as a Picture, regardless of what is the specific content above, by the scanner page into the computer into a graphics file.

\section{A key Grasp of the Archives Database Construction.}

The meaning of database construction is based on advanced information technology to scientific management of materials and easy to use. The construction of the digital archives involves the establishment of the corresponding databases in all aspects of the archives, including the archives of the archives, the catalogs and the catalog files in the volume, the database of important electronic documents, the use of databases and the use of databases and each Such as archiving information database. In the process of building the database should follow the low to high, from a single to the group of principles, the first file directory database construction after the full file database construction.

Tile Information Transmission Platform Digital.

Archival information is only in the delivery process to reflect its value, the previous information exists in a document that is the original file or processed secondary literature, people need archives, often need to visit the archives, through the excerpts, Copy or shoot and other forms to obtain the required information. However, when the file information is digitally present after digitization, the digital network system will become its primary transmission platform, providing the possibility of rapid flow of archival information. Digitized file information can be transmitted in the process of multi-directional transmission at the same time, the formation of transmission network, and through the Internet can be easily remote transmission, free from time and space constraints, users do not have to visit the archives, you can at any time Any location makes it easy to use archival information through a computer. 


\section{Research on the Basic Work of Optimizing the Collection of Archives in Colleges and Universities.}

Investment Funds and Manpower, for the Archives with Information Technology Equipment and Infrastructure.

At present, most of the archives management of colleges and universities is still in a highly dependent stage of human operation, this phenomenon makes the development of university archives management stagnated. In addition, although some colleges and universities in the hardware construction is equipped with a large number of computers, but the actual management work also rely on artificial, a lot of information equipment has become a display. In addition, due to the relevant file management computer software in the preparation process, the computer programmer lack of knowledge of the management of archives, resulting in open management software is not practical, can not be competent university archives management.

The university File Digital Construction, should Pay Attention to cost Control, Pay Attention to Efficiency.

The realization of informationization of archives management in colleges and universities, and the digitization of information dependence. In view of the specific characteristics of university archives, managers should change their thinking through the use of advanced science and technology to promote the realization of digital information, and ultimately provide a better service for the development of colleges and universities. The digital construction of university archives requires a lot of manpower, material and financial support. It needs more efficient cooperation. In the process of specific digital construction, it is necessary to take into account the huge amount of school archives, and it is not necessary to digitize the files used. For the higher value of the file for processing, such archives can be in the social production of greater economic and social benefits; and other categories of archives are temporarily not considered the implementation of digital processing, making the archives information resources, digital efficiency Greatly improved. In the process of digitizing the construction of the entire archives information resources, it is necessary to do the research work of the archival materials, formulate the efficient digitalization plan according to the previous research results, strictly grasp the specific degree of the digital processing of the archives, strictly control the processing cost, Utilization, reduce waste, and reduce follow-up file management costs.

\section{Archives Digital Management Complex Talents Training}

The Key to the Digitalization Construction of Archives in Colleges and Universities is the Cultivation of High Quality and Innovative Talents. We must establish a reasonable division of labor, structural science, excellent quality, strong protection of the file management team. In particular, the efficient file management team should have the following qualities: (1) better policy interpretation ability, higher ideological and political quality; (2) information management concept, team spirit; (3) master modern Management tools and methods.

Higher level of policy and ideological and political quality is an important prerequisite for managers to do a good job in archival management. Archives management is a more cumbersome job requiring managers with strong sense of responsibility, good professionalism and ideological and political qualities. Which is the key to realize the informationization of archives in colleges and universities. Through the establishment of the concept of information service, we strengthen the mutual cooperation among the management teams, so as to realize the information service concept of the university. Archives management work to provide an important guarantee; and through the use of advanced management tools, can effectively improve the level of archives management work in colleges and universities to adapt to the management of information management files to improve the efficiency of file management to effective resource input Greater effectiveness. 


\section{To Achieve the University Archives Digital Countermeasures Research, Efficient File Digital Model Research.}

\section{To Strengthen the Construction of Digital Archives Standard Specification.}

The file digitization standard specification mainly includes the management standard specification, the business standard standard nd the technical standard standard. It mainly includes the standardization of archival information cataloging, the standardization of archival information storage, and the standardization of archives information management software development technology.

\section{The Implementation of Document Integration.}

The implementation of document integration is the premise of digital file construction. This requires the digitization of the file into the general pattern of office automation, and office automation integration, simultaneously. At the same time, archives are also required to actively intervene in this work, put forward archives management and electronic file archiving practical needs.

\section{Insist on Archiving two-track System.}

Archiving Two-track system is the principle that must be adhered to in the transition of paper documents to electronic documents. Although a large number of electronic documents produced and applied, but its legal role and the role of the certificate has not yet replaced the status of paper documents. In the longer period, paper documents and electronic documents will continue to coexist. And in accordance with the requirements of the National Archives, electronic documents must be archived with the same version of paper documents.

\section{Solidly Promote the File Database Construction.}

Archives digital construction must strengthen the database construction, to protect the network of information resources, rich, useful, safe and fast. Strengthening the construction of the document catalog database in order to facilitate the digital construction of important files, so as to build high-quality, high-level full-text information database, in order to achieve all the archives of all digital. Archival information resources Digitalization is the basic conditions and prerequisites for the construction of digital archives, digital archives, digital archives do not play the material basis of their functions; no file resources, Archives intelligent services, file information online transmission is out of the question, the opening of the file and international standards for information exchange, sharing of information resources is also difficult to achieve the desired results.

\section{To Ensure Network Security.}

Ensuring network security is an important task that can not be ignored in the digitization of archives. First, confidential information confidential security issues should be set up access, identity, etc .Second, should take appropriate measures to protect the safety of computer systems running.

In short, through the introduction of platform software, etc. to create a convenient channel to explore efficient file digital mode; quickly completed archives from the storage file base to file information center changes. Archives have established a file information management system platform, completed the archives of all archives information directory-level database, part of the thematic digital library and part of the full text of the database construction. The establishment of the school archives website, the use of the network to receive office automation process in the formation of electronic file information, with the campus network to expand and optimize the file information resources to ensure the information is fast and complete.

\section{References}

[1] Xu Jing; Xu Yinghua, archives digital construction practice exploration [J]. Heilongjiang Archives, 2009 (1)

[2] Zhao Lianfeng, University archives digital construction of the exploration [J.] Fujian Computer, 
$2010(4)$

[3] Zhao Demei, on digital file management [J]. Science and Technology Information Development and Economy, 2006 (21)

[4] Hou bianbian, to speed up the digital construction of colleges and universities should take measures [J]. File management, 2008

[5] Wang Haiou. Japanese archives management and digital archives construction [J]. Sichuan Archives. 2008 (01)

[6] Tang Yanfang, digital archives archives information service platform architecture, archives research, $2006(5)$

[7] Ma Haiqun, etc., the impact of digital information resources construction of the key factors and countermeasures analysis, archives newsletter, 2007 (4)

[8] Lian Zhiying. Digital archives in e-government [J]. Archives Research. 2007 (02)

[9] Fu Rong-xue, Chen Rong-hong.Study on the Mode of Digital Archives (2) - Preliminary Introduction to the Construction Mode of Comprehensive Digital Archives at Present Stage [J]. Archives Newsletter. 2005 (05) 